\title{
A study on ninhydrin reaction with weak acid dissociable cyanide and its application for toxic cyanide determination
}

\author{
Andriana Risk Surleva ${ }^{1,}$, , Sabina Bancila ${ }^{2}$, Elena Veselinova Todorova ${ }^{3}$ \\ ${ }^{1}$ Department of Analytical Chemistry, University of Chemical Technology and Metallurgy, 8 “K1. Ohridski”blvd., Sofia 1756, Bulgaria \\ ${ }^{2}$ Faculty of Chemistry, "Alexandru Ioan Cuza" University, 11 "Carol I" blvd., Ro-7000506 Iasi, Romania \\ ${ }^{3}$ Department of Silicate Technology, University of Chemical Technology and Metallurgy, 8 “Kl. Ohridski”blvd., Sofia 1756, Bulgaria
}

\section{Email address:}

surleva@uctm.edu (A. Surleva), sabina.bancila@yahoo.com (S. Bancila), elito.todorova@gmail.com (E. Todorova)

\section{To cite this article:}

Andriana Risk Surleva, Sabina Bancila, Elena Todorova. A Study on Ninhydrin Reaction with Weak Acid Dissociable Cyanide and Its Application for Toxic Cyanide Determination. Science journal of Analytical Chemistry. Vol. 2, No. 1, 2014, pp. 1-6.

doi: 10.11648/j.sjac.20140201.11

\begin{abstract}
Environmental Protection Agencies impose stringent limits for weak-acid dissociable metal-cyanide complexes (WAD) content in waters. The maximum contaminant level in drinking water is as low as $50 \mu \mathrm{g} / \mathrm{L}$ as $\mathrm{CN}^{-}$. Hence, sensitive methods for WAD cyanide determination are strongly required. Recently, ninhydrin reaction with free cyanide has been proven as a very sensitive at $485 \mathrm{~nm}\left(\varepsilon=1.2 \times 10^{5} \mathrm{~L} / \mathrm{mol} . \mathrm{cm}\right)$, fast $(15 \mathrm{~min})$, selective and with non-toxic reagents. In the presence of free cyanide the absorbance measurement was based on the formation of a red hydrindatin resulting from cyanide's catalytic effect on ninhydrin at $\mathrm{pH} 10.8$. This report presents the results from a study on the reaction between ninhydrin and complexed cyanide at ambient conditions. The WAD complexes: $\mathrm{Hg}(\mathrm{CN})_{4}{ }^{2-} ; \mathrm{Ni}(\mathrm{CN})_{4}{ }^{2-} ; \mathrm{Cu}(\mathrm{CN})_{4}{ }^{3-} ; \mathrm{Ag}(\mathrm{CN})_{2}{ }^{-}$; $\mathrm{Zn}(\mathrm{CN})_{4}{ }^{2-} ; \mathrm{Cd}(\mathrm{CN})_{4}{ }^{2-}$ are discussed. The reaction kinetic and standard curves are presented. Ligand exchange approach was applied without additional separation. Ninhydrin was showed to be selective and sensitive for direct cyanide quantification.
\end{abstract}

Keywords: Weak Acid Dissociable Cyanide, Ninhydrin, Spectrophotometry, Ligand Exchange

\section{Introduction}

Water Authorities have divided cyanide compounds into three groups according to their toxicity and environmental fate: (1) free cyanide ( $\mathrm{HCN}$, water soluble cyanide salts) referred as the most toxic cyanide compounds; (2) weak acid dissociable cyanide (WAD) includes free cyanide and metal-cyanide complexes which easily dissociate and release $\mathrm{HCN}$ at environmental conditions; (3) total cyanide all compounds containing $\mathrm{CN}$ group. Stringent requirements to WAD cyanide levels in waste and natural waters as well as the sensitivity and reliability of the analytical methods for WAD cyanide determination have been imposed [1-4]. Maximum permissible levels for WAD cyanide in waste waters is as low as $100 \mu \mathrm{g} / \mathrm{L}$ and in portable water $-50 \mu \mathrm{g} / \mathrm{L}$. Very low levels of free cyanide $(5 \mu \mathrm{g} / \mathrm{L})$ is reported to be lethal for aquatic life.

Recently, free cyanide in trace concentration levels was quantified using ninhydrin as a chromogenic reagent $[5,6]$. Ninhydrin and cyanide formed an intensively red colored adduct in sodium carbonate medium with molar absorptivity of $1.2 \times 10^{5} \mathrm{~L} / \mathrm{mol} . \mathrm{cm}$ at $485 \mathrm{~nm}$ [7]. The limit of detection and quantification were 8 and $22 \mu \mathrm{g} \mathrm{CN} / \mathrm{L}$, respectively. The reaction was implemented in flow injection and cuvetteless spectrophotometry for free cyanide determination after separation by on-line gas-diffusion or head-space extraction [8-10].

However the determination of weak acid dissociable cyanide has still being a challenge for researchers from two scientific domains. From the toxicological point of view, the cyanide bound in weak-acid dissociable complexes is considered as a very toxic since it is easily liberated at environmental conditions and is available to form $\mathrm{HCN}-\mathrm{a}$ severe poison, and the Ecological Agencies stipulate for sensitive and reliable methods for WAD cyanide determination. From the analytical point of view, the ninhydrin reaction with cyanide being very sensitive, fast, selective and with non-toxic reagents, is appropriate for implementation for sensitive WAD cyanide determination by spectrophotometry. Recently, the research interest have been directed to WAD quantification and a line of methods 
were developed based on different approaches for cyanide liberation and separation: ligand exchange, $\mathrm{HCN}$ formation in acidic solutions and gas-diffusion separation [8, 11-14] or head-space extraction [10,15]; ligand exchange combined standard distillation procedure [10], chromatographic or capillary electrophoresis [15] techniques.

Ninhydrin-cyanide reaction was proved to be strongly interfered by mercury (II), cooper (II) and silver (I), and at less extent by $\mathrm{Ni}^{2+}, \mathrm{Zn}^{2+}$ and $\mathrm{Cd}^{2+}[16,17]$. However, a possible implementation of ninhydrin reagent for complex cyanide determination was supposed based on following facts: (1) cyanide bounded in complexes with $\mathrm{Hg}(\mathrm{II}) ; \mathrm{Cu}(\mathrm{I})$ and $\operatorname{Ag}(\mathrm{I})$ is 2-4 times more than the metal ion and respectively the equilibrium concentration of cyanide is higher than metal ion concentration; (2) in cooper-cyanide complex $\mathrm{Cu}(\mathrm{I})$ is involved and its reaction with ninhydrin has not been studied; (3) two competing reactions could be supposed metal-ninhydrin and cyanide-ninhydrin and difference in the reaction rates could be explored. This study is aimed at the investigations of the reaction between ninhydrin and WAD cyanide and the possibilities for its application for WAD cyanide determination. The following WAD cyanide complexes: $\mathrm{Hg}(\mathrm{CN})_{4}{ }^{2-} ; \mathrm{Ni}(\mathrm{CN})_{4}{ }^{2-} ; \mathrm{Cu}(\mathrm{CN})_{4}{ }^{3-}$; $\mathrm{Ag}(\mathrm{CN})_{2}{ }^{-} ; \mathrm{Zn}(\mathrm{CN})_{4}{ }^{2-} ; \mathrm{Cd}(\mathrm{CN})_{4}{ }^{2-}$ were studied in the range $(0.38 \div 3.8) \times 10^{-6} \mathrm{~mol} / \mathrm{L} \mathrm{CN}^{-}$. Ligand exchange approach and ninhydrin based detection without additional separation was studied. Cysteine, thiourea and tetraethylenepentamine were chosen as they were reported to give complete recovery in different combinations with sulfur or amine based ligands for on-line gas-diffusion flow-injection determination of WAD cyanide [11, 14]. Moreover, it was described that cysteine did not interfere with ninhydrin-cyanide reaction, but quantitative data were not provided [17]. This report presents the results from a study on the ninhydrin-WAD cyanide reaction in the presence of ligand exchange reagents without separation of liberated cyanide ions.

\section{Experimental}

\subsection{Reagents and Standard Solutions}

Stock solution of potassium cyanide was standardized titrimetrically by silver nitrate standard solution. WAD cyanide standard solutions $\left(10^{-2} \mathrm{M}\right)$ were prepared by adding the stoichiometric quantity of standard $\mathrm{KCN}$ solution to $\mathrm{Hg}(\mathrm{CN})_{2}, \mathrm{Zn}(\mathrm{CN})_{2}, \mathrm{CuCN}$ and $\mathrm{AgCN}$ salts. Standard solutions of $\mathrm{Ni}(\mathrm{CN})_{4}{ }^{2-}$ and $\mathrm{Cd}(\mathrm{CN})_{4}{ }^{2-}$ were prepared by dissolving of $\mathrm{NiCl}_{2}$ or $\mathrm{CdSO}_{4}$ in stoichiometric quantity of $\mathrm{KCN}$. Working solutions were prepared daily by dilution of appropriate aliquots from stock solution in $10^{-2} \mathrm{M} \mathrm{NaOH}$. Ninhydrin solution was also daily prepared by dissolving $150 \mathrm{mg}$ of ninhydrin in $50 \mathrm{~mL}$ of $2 \% \mathrm{Na}_{2} \mathrm{CO}_{3}$, purged with nitrogen for $15 \mathrm{~min}$. Standard solutions were purged with nitrogen. Cysteine, cystin, thiourea and tetraethylenepentamine hydrochloride (all Fluka reagents) were used. All reagents were of analytical grade.

\subsection{Instrumentation and Procedures}

Standard solutions of $\mathrm{Hg}(\mathrm{CN})_{4}{ }^{2-}, \mathrm{Zn}(\mathrm{CN})_{4}{ }^{2-}, \mathrm{Cu}(\mathrm{CN})_{4}{ }^{3-}$, $\mathrm{Ni}(\mathrm{CN})_{4}{ }^{2-} \mathrm{Cd}(\mathrm{CN})_{4}{ }^{2-}$ and $\mathrm{Ag}(\mathrm{CN})_{2}{ }^{-}$at concentrations from 1 $\times 10^{-6}-3.5 \times 10^{-6} \mathrm{M}$ (calculated as $\mathrm{CN}^{-}$) were prepared by adding appropriate volumes of WAD cyanide solutions (7.7 $\times 10^{-5} \mathrm{M}$ as $\left.\mathrm{CN}^{-}\right)$into $10 \mathrm{~mL}$ measuring flasks, a volume of $3.3 \mathrm{~mL}$ of ninhydrin reagent $(3 \mathrm{mg} / \mathrm{mL}$ ninhydrin in $2 \%$ $\mathrm{Na}_{2} \mathrm{CO}_{3}$ ) was added to each standard solution and the volume was made up to $10 \mathrm{~mL}$ by $2 \% \mathrm{Na}_{2} \mathrm{CO}_{3}$ (purged with nitrogen). The mixture was homogenized and left for $15 \mathrm{~min}$ for color development. A blank solution was prepared diluting $3.3 \mathrm{~mL}$ of ninhydrin reagent up to $10 \mathrm{~mL}$ with $2 \%$ $\mathrm{Na}_{2} \mathrm{CO}_{3}$. UV-Vis absorption spectra at wavelength range from 300 to $700 \mathrm{~nm}$ were acquired on a LIBRA S35 PC UV/VIS spectrophotometer (Biochrom, Cambridge, England) in 1-cm quartz cuvettes against blank containing 1 $\mathrm{mg} / \mathrm{mL}$ ninhydrin in $2 \% \mathrm{Na}_{2} \mathrm{CO}_{3}$. Kinetics measurements were made measuring the absorbance of WAD cyanide-ninhydrin mixture at $485 \mathrm{~nm}$ at every two minutes up to 60 min using the reaction kinetics mode of Acquire Application Software (Biochrom, Cambridge, England). Single wavelength absorbance measurements were made on Specol 11 spectrophotometer in 1-cm quartz cuvettes. In differential spectrophotometry the absorbance was measured against a reference containing: $1.5 \times 10^{-6} \mathrm{M} \mathrm{CN}^{-}$ and $1 \mathrm{mg} / \mathrm{mL}$ ninhydrin in $2 \% \mathrm{Na}_{2} \mathrm{CO}_{3}$.

\subsection{Ligand Exchange Procedure}

A sample aliquot of $2 \mathrm{~mL}$ containing metal-cyanide complex $\left(7.7 \times 10^{-5} \mathrm{M}\right.$ as $\left.\mathrm{CN}^{-}\right)$was transferred in a beaker and $2 \mathrm{~mL}$ of ligand exchange reagent $\left(1.54 \times 10^{-4} \mathrm{M}\right)$ were added. The mixture was agitated on magnetic stirrer for 40 min at room temperature. Three aliquots from the obtained solution were taken and transferred in measuring flasks, 3.3 $\mathrm{mL}$ of ninhydrin reagent was added and the volume was made up to $10 \mathrm{~mL}$ by $2 \% \mathrm{Na}_{2} \mathrm{CO}_{3}$. The solutions were left for $15 \mathrm{~min}$ for color development. The absorbance of each sample was measured at $490 \mathrm{~nm}$ against reference containing $1.5 \times 10^{-6} \mathrm{M} \mathrm{CN}^{-}$.

\section{Results and Discussion}

\subsection{Comparative Study of Ninhydrin-Based Protocols for Free Cyanide Determination}

One-step protocol, firstly described by Drochioiu [5], was based on the reaction between cyanide and ninhydrin in $2 \%$ sodium carbonate solution at ambient conditions and monitoring the absorbance of the obtained red solution at $485 \mathrm{~nm}$. In sodium carbonate medium cyanide reacted with ninhydrin forming a red colored ninhydrin-cyanide adduct: 2-cyano-1,2,3-trihydroxy-2H indene [16]. Two-step protocol, firstly described by Nagaraja, Kumar, Yathiraja, and Prakash [6], was based on: firstly, formations of a red colored ninhydrin-cyanide adduct in sodium carbonate media, and secondly, formation of blue colored compound 
upon addition of sodium hydroxide. The absorbance of the blue solution at $590 \mathrm{~nm}$ was monitored. Fig. 1 presents the spectra of ninhydrin-cyanide adduct in sodium carbonate solution before and after addition of sodium hydroxide. As can be seen from the Fig. 1, the addition of $\mathrm{NaOH}$ to the red colored ninhydrin-cyanide adduct (monovalent ion) solution caused color transition from red to blue (divalent ion). A bathochromic shift from 485 to $590 \mathrm{~nm}$ was observed. The molar absorptivities of red and blue compounds at $485 \mathrm{~nm}$ and $590 \mathrm{~nm}$ were: $1.4 \times 10^{5} \mathrm{~L} / \mathrm{mol} . \mathrm{cm}$ and $8.8 \times 10^{4}$ L/mol.cm, respectively.

The bathochromic shift has been already reported $[6,18$, 19]. However, in contrast to the reported results, the absorbance of the blue colored compound at $590 \mathrm{~nm}$ was lower than the absorbance of the red colored one at $485 \mathrm{~nm}$. The observed lowering of the absorbance was independent of neither cyanide nor $\mathrm{NaOH}$ concentrations. The effect was probably due to the instability of colored compound at high $\mathrm{pH}$ in the presence of oxygen. Moreover, at $\mathrm{pH}>13$ a peak at $352 \mathrm{~nm}$ was observed (Fig. 1). As can be seen from the Figure, the blue color of obtained compound vanished with time, quicker in more alkaline solution. The stability of the blue colored compound was lower when compared to the stability of the red colored one - the blue color totally disappeared in 24 hours, while the red solution was found intensively colored. From analytical point of view, a one-step procedure seems to be a better choice due to its simplicity and better stability of the colored adduct.

\subsection{Ninhydrin - Free Cyanide Reaction}

The mechanism of ninhydrin-cyanide reaction was thoroughly discussed in [16]. Here we confine our study to the low concentration region $\left(1-3 \times 10^{-6} \mathrm{M}\right)$. It was noticed that although the calibration curve was linear an intercept was obtained. We supposed that it is due to the particularity of the two stage ninhydrin-cyanide reaction involving two molecules of $\mathrm{KCN}$ in the formation of the red-colored ninhydrin-cyanide adduct and to the existence of a critical concentration of $\mathrm{KCN}$ necessary to provoke the reaction. At higher cyanide concentrations, the reaction may follow different mechanism. Thus a modified equation of Beer's law was used $A=a+b * C$, where $A$ is the absorbance, $C$ is the concentration of the cyanide-ninhydrin adduct $(\mathrm{mol} / \mathrm{L})$, a and $b$ denote the coefficients of the linear calibration curve. The mean calibration coefficients in the concentration interval $(0.7 \div 2.6) \times 10^{-6} \mathrm{M}$ were: slope $(4.32 \pm 0.08) \times 10^{5}$ and intercept $(-0.247 \pm 0.073)(\mathrm{n}=6 ; \mathrm{P}=95 \%)$. The slope and intercept were independent of the reaction time in the interval 15 - $30 \mathrm{~min}$. The differential spectrophotometric measurements were also studied in the environmentally important concentration interval $(0.7-3.85) \times 10^{-6} \mathrm{M} \mathrm{CN}^{-}$. The coefficients of the regression line obtained by measuring the absorbance against reference containing 1.54 $\times 10^{-6} \mathrm{M} \mathrm{CN}^{-}$were: slope $(5.61 \pm 0.05) \times 10^{5}(\mathrm{n}=3 ; \mathrm{P}=95 \%)$ and intercept $-(-0.820 \pm 0.050)$. As can be seen from the results, at 0.05 confidence interval both slopes were not statistically different and differential spectrophotometry could be used in studied concentration range.
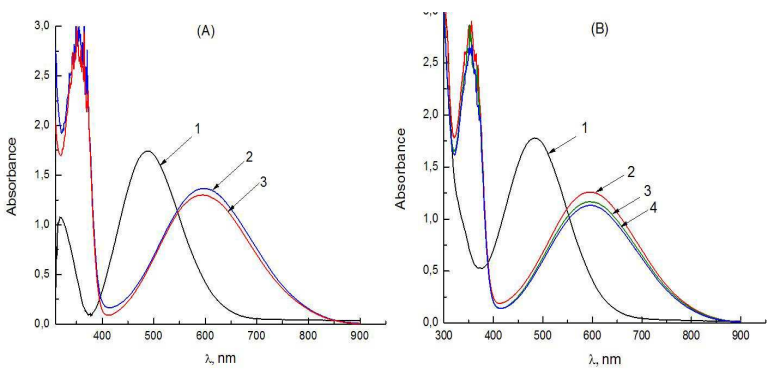

Figure 1 Spectra of ninhydrin-cyanide adduct, $C_{C N}=0.3 \mu \mathrm{g} / \mathrm{mL}$ in $2 \%$ $\mathrm{Na}_{2} \mathrm{CO}_{3}: 1$, before and 2, after addition of $\mathrm{NaOH}$ : (A) final $\mathrm{C}_{\mathrm{NaOH}}=0.7 \mathrm{M} ; 2$, 30 seconds; 3, 5 min after addition of $\mathrm{NaOH}$ and (B) final $\mathrm{C}_{\mathrm{NaOH}}=0.1 \mathrm{M} ; 2$, $1 \mathrm{~min} ; 3,10 \mathrm{~min} ; 4,15 \mathrm{~min}$ after addition of $\mathrm{NaOH}$.

\subsection{Ninhydrin - Complexed Cyanide Reaction}

The spectra of ninhydrin-cyanide adduct obtained from complex cyanide are presented in Fig. 2. The wavelength of maximum absorption $(490 \mathrm{~nm})$ coincided well with the $\lambda_{\max }$ of $\mathrm{CN}^{-}$in the case of $\mathrm{Hg}(\mathrm{CN})_{4}{ }^{2-} ; \mathrm{Ni}(\mathrm{CN})_{4}{ }^{2-}$;

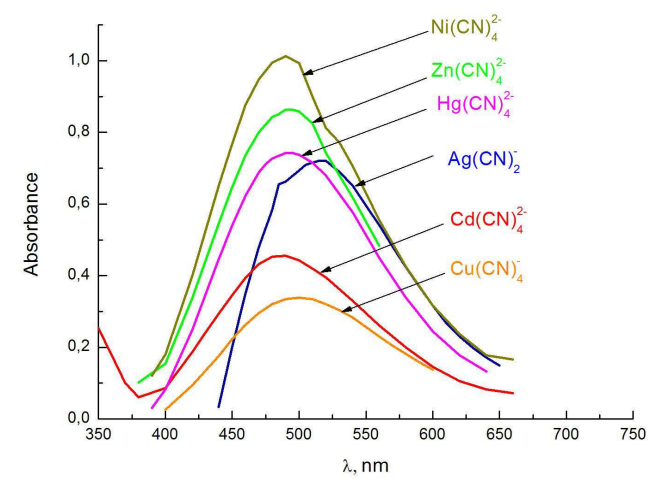

Figure 2 Spectra of WAD cyanide - ninhydrin adduct.

$\mathrm{Cu}(\mathrm{CN})_{4}{ }^{3-} ; \mathrm{Zn}(\mathrm{CN})_{4}{ }^{2-} ; \mathrm{Cd}(\mathrm{CN})_{4}{ }^{2-}$. A red shift of $25 \mathrm{~nm}$ was observed in the case of $\operatorname{Ag}(\mathrm{CN})_{2}^{-}$. The calibration curves were obtained for each WAD complex; the linear range, equations and recoveries are presented in Table 1.

In the case of $\mathrm{Hg}(\mathrm{CN})_{4}{ }^{2-}$, although linear fit of the data was good enough for quantitative determination, the polynomial fitting resulted in better correlation $\mathrm{r}=0.999(\mathrm{Y}$ $\left.=0.01+4 \times 10^{4} \mathrm{x}+2.1 \times 10^{5} \mathrm{x}^{2}\right)$. Hence, a catalytic mechanism of the reaction between $\mathrm{Hg}(\mathrm{CN})_{4}{ }^{2-}$ and ninhydrin could be supposed. The calibration data sets (for $15 \mathrm{~min}$ color development reaction time) were compared with calibration data obtained using free cyanide and the results showed that (at the 0.05 significance level) the data sets were not statistically different for $\mathrm{Hg}(\mathrm{CN})_{4}{ }^{2-}$; $\mathrm{Zn}(\mathrm{CN})_{4}{ }^{2-}$ and $\mathrm{Cd}(\mathrm{CN})_{4}{ }^{2-}$. The $\mathrm{Cu}(\mathrm{CN})_{4}{ }^{3-}$ and $\mathrm{Ag}(\mathrm{CN})_{2}{ }^{-}$ calibration curves were linear, but with lower absorbance values compared to $\mathrm{CN}^{-}$calibration curve. In the reaction between ninhydrin and $\mathrm{Fe}(\mathrm{CN})_{6}{ }^{3-}$ no color compound was obtained even after 60 min reaction time. $\mathrm{Fe}(\mathrm{CN})_{6}{ }^{3-}$ is regarded as non-toxic cyanide complex and the results showed the selectivity of ninhydrin reagent for WAD cyanide determination. 
Table 1 Calibration parameters and recovery study for WAD cyanide.

\begin{tabular}{|c|c|c|c|c|c|}
\hline Me-cyanide complex & $\begin{array}{c}\text { Concentration } \\
\text { range } \times 10^{-6-} \mathrm{CN} / \mathrm{M}\end{array}$ & Calibration equation & Correlation coefficient & Total cyanide recovery/\% ${ }^{a}$ & $\begin{array}{c}\text { Total cyanide recovery/\% } \\
b\end{array}$ \\
\hline $\mathrm{Hg}(\mathrm{CN})_{4}{ }^{2-}$ & $0.5-2.0^{\mathrm{c}}$ & $-0.206+4.8 \times 10^{5} \mathrm{C}$ & $\begin{array}{l}0.9871 \\
(\mathrm{n}=6)\end{array}$ & 97.1 & 100.8 \\
\hline $\mathrm{Ni}(\mathrm{CN})_{4}{ }^{2-}$ & $0.7-3.1^{\mathrm{d}}$ & $-0.060+3.6 \times 10^{5} \mathrm{C}$ & $\begin{array}{l}0.9969 \\
(\mathrm{n}=7)\end{array}$ & 99.1 & 102.4 \\
\hline $\mathrm{Cd}(\mathrm{CN})_{4}{ }^{2-}$ & $1.3-3.6^{\mathrm{d}}$ & $-0.164+3.2 \times 10^{5} \mathrm{C}$ & $\begin{array}{l}0.9945 \\
(\mathrm{n}=8)\end{array}$ & 108.4 & 95.0 \\
\hline $\mathrm{Zn}(\mathrm{CN})_{4}{ }^{2-}$ & $0.5-2.1^{\mathrm{c}}$ & $-0.226+5.2 \times 10^{5} \mathrm{C}$ & $\begin{array}{l}0.9969 \\
(\mathrm{n}=7)\end{array}$ & 102.5 & 111.0 \\
\hline $\mathrm{Cu}(\mathrm{CN})_{4}{ }^{3-}$ & $0.5-2.1^{\mathrm{c}}$ & $-0.122+2.8 \times 10^{5} \mathrm{C}$ & $\begin{array}{l}0.9888 \\
(\mathrm{n}=6)\end{array}$ & 98.0 & 55.4 \\
\hline $\mathrm{CN}^{-}$ & $0.5-2.6^{\mathrm{d}}$ & $-0.155+2.9 \times 10^{5} \mathrm{C}$ & $\begin{array}{l}0.9992 \\
(\mathrm{n}=8)\end{array}$ & - & 103.1 \\
\hline
\end{tabular}

a. Recovery at total cyanide concentration $1.26 \times 10^{-6} \mathrm{M}$ calculated according WAD cyanide curve.

b. Recovery at total cyanide concentration $1.26 \times 10^{-6} \mathrm{M}$ calculated according free cyanide curve.

c. Ninhydrin concentration $5 \mathrm{mg} / \mathrm{mL}$

d. Ninhydrin concentration $3 \mathrm{mg} / \mathrm{mL}$

The kinetics study of $\mathrm{Me}(\mathrm{CN})_{4}{ }^{\mathrm{n}-}$ - ninhydrin reaction showed that a constant absorbance was obtained after 30 min, which is two times more than ninhydrin-free cyanide reaction (Fig. 3A). Based on these results we supposed that the ninhydrin- $\mathrm{Me}(\mathrm{CN})$ reaction was controlled by the rate of cyanide liberation from the complex. $\mathrm{Hg}(\mathrm{CN})_{4}{ }^{2-}$ and $\mathrm{Cu}(\mathrm{CN})_{4}{ }^{3-}$ seemed to be more inert in the studied conditions than $\mathrm{Zn}(\mathrm{CN})_{4}^{2-}$ and $\mathrm{Cd}(\mathrm{CN})_{4}^{2-}$. To enhance the cyanide liberation cysteine was added as a ligand exchange reagent.
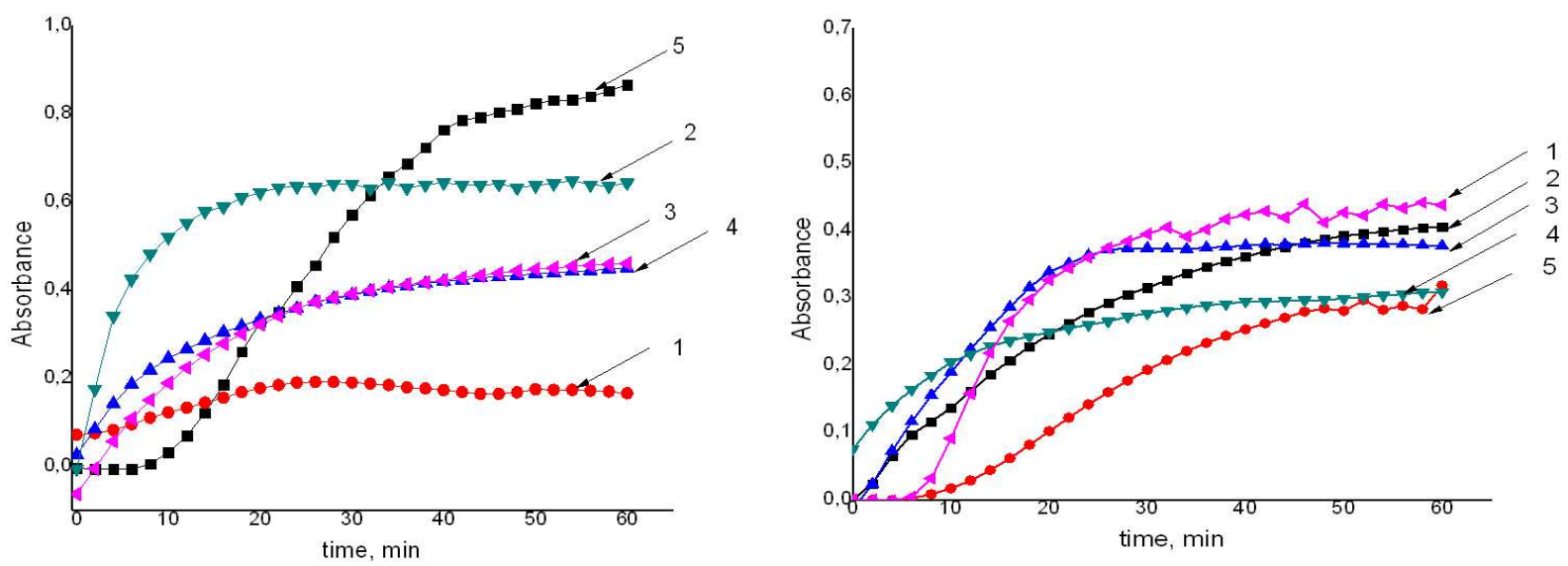

Figure 3 Kinetic curves of WAD cyanide-ninhydrin (A) and WAD cyanide-ninhydrin-cysteine (B) reactions at 485 nm against dist. $\mathrm{H}_{2} \mathrm{O}: 1, \mathrm{Hg}(\mathrm{CN}){ }_{4}^{2-} ; 2$, $\mathrm{Zn}(\mathrm{CN})_{4}{ }^{2-} ; 3, \mathrm{Cd}(\mathrm{CN})_{4}{ }^{2-} ; 4, \mathrm{Cu}(\mathrm{CN})_{4}{ }^{3-} ; 5, \mathrm{Ag}(\mathrm{CN})_{2}$

The $\mathrm{Me}(\mathrm{CN})_{4}{ }^{\mathrm{n}-}$ reaction with ninhydrin in the presence of cysteine was followed spectrophotometrically at $485 \mathrm{~nm}$ (Fig. 3B). Two reactions might be supposed: (1) a reaction between $\mathrm{Hg}^{2+}$ with cysteine and (2) a reaction between liberated $\mathrm{CN}^{-}$and ninhydrin. As can be seen from the Figure, in the presence of cysteine the reaction is slower during the first $6 \mathrm{~min}$ and rapidly increased in rate. The slope of the initial part of the curve (b) is higher compared with the curve without cysteine. In both cases the stable absorbance was observed after $30 \mathrm{~min}$. The absorbance intensity increased in the presence of cysteine. Maximum absorbance was reached after $30 \mathrm{~min}$ from the beginning of the reaction.

\subsection{Ligand Exchange Approach for Complexed Cyanide Liberation}

Although the waste water samples contain WAD complexes in different molar ratios and excess of free cyanide, we studied ligand exchange reaction in the most unfavorable case: the studied model samples contained $100 \%$ of complexed cyanide and no free cyanide. The kinetic curves of ninhydrin-cyanide reaction in the presence of cysteine, presented on Fig 3B, showed that at least 30 min were necessary to obtain constant absorbance. Hence, we proposed the following procedure for WAD cyanide quantification: cysteine was added to the WAD cyanide sample in molar ratio $1: 2$ and agitated for $40 \mathrm{~min}$ at room temperature $\left(30^{\circ} \mathrm{C}\right)$; the aliquots were taken and transferred in $2 \% \mathrm{Na}_{2} \mathrm{CO}_{3}$ solution, ninhydin reagent was added and sample was left for $15 \mathrm{~min}$ for color development. 


\subsection{Recovery Study}

The efficiency of ninhydrin reagent for direct cyanide measuring after ligand exchange step was evaluated by recovery study. Different ligand exchange reagents were studied: cystine, cysteine, thiourea, tetraethylenepentamine and combined sulphur and amine based ligands. Free cyanide sample was also passed through the ligand exchange step as a control sample for interference. The results are presented on Table 2.

The highest recovery for all WAD complexes was obtained after thiourea ligand exchange and reaction of liberated cyanide with ninhydrin. However, for $\mathrm{Cu}(\mathrm{CN})_{4}{ }^{3-}$ complex the recovery was still below $50 \%$, better results were obtained at higher molar ratio metal:ligand.

Table 2 Recovery study of total cyanide from WAD complexes by ligand exchange ${ }^{a}$

\begin{tabular}{|c|c|c|c|c|c|}
\hline \multirow{2}{*}{$\begin{array}{c}\text { Me-cyanide } \\
\text { complex }\end{array}$} & \multicolumn{5}{|c|}{ Recovery/\% } \\
\hline & Cystine & Thiourea & Cysteine & Cysteine + TEPA & Thiourea + TEPA \\
\hline $\mathrm{Hg}(\mathrm{CN})_{4}{ }^{2-}$ & $87.7 \pm 0.2$ & $105.6 \pm 0.4$ & $74.4 \pm 1.3$ & $94.7 \pm 0.1$ & $94.3 \pm 0.5$ \\
\hline $\mathrm{Ni}(\mathrm{CN})_{4}{ }^{2-}$ & $50.5 \pm 0.8$ & $85.0 \pm 0.4^{\mathrm{a}} / 92.4^{\mathrm{b}}$ & $47.8 \pm 0.3$ & $77.2 \pm 0.5$ & $82.1 \pm 0.7$ \\
\hline $\mathrm{Cd}(\mathrm{CN})_{4}{ }^{2-}$ & $81.6 \pm 0.3$ & $83.0 \pm 1.1$ & $72.8 \pm 0.1$ & $83.7 \pm 0.1$ & $88.9 \pm 0.2$ \\
\hline $\mathrm{Zn}(\mathrm{CN})_{4}{ }^{2-}$ & $93.5 \pm 0.4$ & $108.9 \pm 1.1$ & - & $116.7 \pm 0.2$ & $109.0 \pm 0.2$ \\
\hline $\mathrm{Cu}(\mathrm{CN})_{4}{ }^{3-}$ & $48.2 \pm 1.6$ & $41.4 \pm 0.1^{\mathrm{a}} / 77.3^{\mathrm{b}}$ & $50.6 \pm 0.1$ & $68.0 \pm 0.5$ & $59.5 \pm 0.7$ \\
\hline $\mathrm{Ag}(\mathrm{CN})_{2}^{-}$ & $23.9 \pm 1.5$ & $74.9 \pm 0.3^{\mathrm{a}} / 72.5^{\mathrm{b}}$ & $61.8 \pm 1.3$ & $63.2 \pm 0.3$ & $47.4 \pm 1.2$ \\
\hline $\mathrm{CN}^{-}$ & $91.2 \pm 1.1$ & $98.9 \pm 0^{\mathrm{a}} / 111^{\mathrm{b}}$ & $81.6 \pm 0.4$ & $91.2 \pm 0.3$ & $93.1 \pm 0.2$ \\
\hline
\end{tabular}

a. Molar ratio Me:thiocarbamide $=0.012$. Total cyanide concentration at ligand exchange step: $3.85 \times 10^{-5} \mathrm{M}$. Cyanide concentration at absorbance measuring step: $1.9 \times 10^{-6} \mathrm{M}$.

b. Molar ratio Me:thiocarbamide $=0.06 ; \mathrm{C}_{\mathrm{CN}}=2.57 \times 10^{-5} \mathrm{M}$.

c. Confidence interval was calculated at $\mathrm{n}=3$ (absorbance was measured in triplicate) and $\mathrm{P}=95 \%$.

The free cyanide recovery has showed that ninhydrin is selective towards cyanide in the presence of ligand exchange reagents.

\section{Conclusions}

The present report has demonstrated the efficiency of ninhydrin as a colorimetric reagent for weak acid cyanide determination. Two protocols for free cyanide determination were compared and the results showed that the measurement of the absorbance of the red colored cyanide-ninhydrin adduct at $\mathrm{pH} 10.8$ maintained by sodium carbonate was more reliable than the procedure involving transformation of red colored adduct into blue one at $\mathrm{pH}>12$, where less stable $\mathrm{pH}$ dependent product was obtained. The results presented here proved the applicability of the reaction between metal-cyanide complexes and ninhydrin for direct WAD cyanide determination. For total WAD cyanide determination the ligand exchange approach was applied. Complexed cyanide was liberated using ligand exchange.
The described protocol was selective towards WAD cyanide in the presence of iron-cyanide complexes regarded as non-toxic cyanide forms. The selectivity of ninhydrin towards liberated cyanide in the presence of ligand exchange reagent is a base for skipping of separation step and simplifying the analytical procedure.

\section{Acknowledgments}

The financial support of the University of Chemical Technology and Metallurgy, Sofia, Bulgaria through the Science and Research Program (Contact Nr 11132/2013) and of the European Social Fund through the Human Resources Program (Contract BG051PO001-3.3.06-0014) was gratefully acknowledged.

\section{References}

[1] United States Environmental Protection Agency, $\mathrm{http} / / /$ water.epa.gov/drink/contaminants/basicinformation/cy anide.cfm, last accessed 15 May 2013

[2] BG Ordinance $\mathrm{Nr} 9$ of 16.03 .2001 on the quality of water intended for drinking purposes

[3] Official Journal of the EuropeanUnion, Commission Directive 1998/83/EC, 1998.

[4] Official Journal of the European Union. Commission Directive 2003/40/EC, 2003.

[5] G. Drochioiu, „Highly selective and sensitive reaction of cyanide with 2,2-dihydroxy-1,3-indanedione", Anal. Bioanal. Chem., vol. 372, pp. 744-747, 2002.

[6] P. Nagaraja, M. Kumar, H. Yathiraja, Prakash, "Novel Sensitive Spectrophotometric Method for the Trace Determination of Cyanide in Industrial Effluent", J. Anal. Sci., vol. 18, 1027-1030, 2002.

[7] A. Surleva, G. Drochioiu, "A Modified Ninhydrin Micro-assay for Determination of Total Cyanogens in Plants", Food Chem., vol. 141, pp. 2788-2794, 2013

[8] D. Themelis, S. Karastogianni, P. Tzanavaras, "Selective Determination of Cyanides by Gas Diffusion-stopped Flow-sequential Injection Analysis and an On-line Standard Addition Approach", Anal. Chim. Acta, vol. 632, pp. 93-100, 2009.

[9] R. Santelli, A. Micelli, “Automated Flow Injection Method for Monitoring Total Cyanide Concentration in Petroleum Refinery Effluents Using Ninhydrin as Color Reagent", Spect. Lett., vol. 39, pp. 605-618, 2006.

[10] A. Jain, A. K. K. V. Pillai, N. Sharma, K. K. Verma, "Headspace Single-drop Microextraction and Cuvetteless Microspectrophotometry for the Selective Determination of Free and Total Cyanide Involving Reaction with Ninhydrin", Talanta, vol. 82, pp. 758-765, 2010.

[11] H. Sulistyarti, S. Kolev, "Online Ligand Exchange in the Determination of Weak Acid Dissociable Cyanide by Gas Diffusion-flow Injection Analysis", Microchem. J., vol. 111, pp. 103-107, 2013. 
[12] J. Favero, M. Tubino, "Semi-quantitative "Spot-test" of Cyanide", Anal. Sci., vol. 19, pp. 1139-1143, 2003.

[13] E. Mirales, D. Prat, R. Compano, M. Grenados, "On-line Gas-diffusion Separation and Fluorimetric Detection for the Determination of Acid Dissociable Cyanide", Analyst, vol. 123, pp. 217-220, 1998.

[14] J. Sebroski, R. Ode, "Method Comparison and Evaluation for the Analysis of Weak Acid-dissociable Cyanide", Environ. Sci. Technol. 1997, vol. 31, pp. 52-57, 1997.

[15] S. Jermak, B. Pranaityte, A. Padarauskas, "Ligand Displacement, Headspace Single-drop Microextraction, and Capillary Electrophoresis for the Determination of Weak Acid Dissociable Cyanide", J. Chromatogr. A, vol. 1148, 123. 2007

[16] G. Drochioiu, L. Mangalagiu, E. Avram, K. Popa, A. C.
Dirtu, L. Druta, "Cyanide Reaction with Ninhydrin: Elucidation of Reaction and Interference", Anal. Sci., vol. 20, pp. 1443-1447, 2004.

[17] I. M. Mihaescu, "Cyanide Determination with a Modified Ninhydrin Reagent using N-Acetyl Cysteine in the Presence of Heavy Metal Ions", J. Chil. Chem. Soc., vol. 55, pp 467-468, 2010.

[18] I. M. Mihaescu, G. Drochioiu, "Cyanide reaction with ninhydrin: the effect of $\mathrm{pH}$ changes and UV-VIS radiation upon the analytical results", Rev. Rom. Chim., vol. 54, pp. 841-845, 2009.

[19] A. Mohammad, M.Z.A.Rafiquee, Inamuddin, A. Amin, "Surfactant Assisted Spectrophotometric Determination Of Glyphosate In Its Formulation", Anal. Chem. Indian J, vol. 10, pp 38-41, 2011. 